\title{
DELIMITAÇÃO E QUANTIFICAÇÃO DA VEGETAÇÃO NATURAL NAS IMEDIAÇÕES DO RIO PARANAÍBA NO MUNICÍPIO DE SÃO SIMÃO-GO
}

\author{
Acácio Mariano Ferreira Neto ${ }^{1}$ \\ Diego Oliveira de Aquinos ${ }^{2}$ \\ Jussara dos Santos Rosendo ${ }^{3}$
}

\begin{abstract}
RESUMO
O presente trabalho foi desenvolvido para a disciplina de Sensoriamento Remoto no terceiro período do curso de Geografia, da Faculdade de Ciências Integradas do Pontal (FACIP), Campus fora de sede da Universidade Federal de Uberlândia (UFU). O mapeamento e a análise das áreas de preservação permanentes são de fundamental importância para garantir a qualidade dos recursos hídricos. Desse modo, o objetivo do presente trabalho foi delimitar e quantificar as áreas de vegetação natural nas imediações do rio Paranaíba, mais precisamente no lago da Usina Hidrelétrica de São Simão-GO. Foi utilizado para a análise a imagem do referido município que advém do sensor TM do satélite Landsat 5, empregando o Sistema de Informações Geográficas (SIG) brasileiro SPRING, versão 5.2.6, no tratamento da imagem, fazendo em seguida a classificação supervisionada para, então calcular os percentuais dos tipos de uso e ocupação do solo.
\end{abstract}

PALAVRAS CHAVE: Sensoriamento Remoto, vegetação natural, análise.

\section{LIMITS AND MEASUREMENT OF NATURAL VEGETATION NEARBY THE PARANAÍBA RIVER IN THE MUNICIPALITY OF SÃO SIMÃO-GO}

\begin{abstract}
This work was developed for Remote Sensing discipline in the third period of Geography course, the Faculdade de Ciências Integradas do Pontal (FACIP), Campus outside the headquarters of the Universidade Federal de Uberlândia (UFU). The mapping and analysis of permanent preservation areas are of fundamental importance to ensure the quality of water resources. Thus, the aim of this study was to define and quantify areas of natural vegetation in the vicinity of Rio Paranaíba, more precisely in the lake of Hydroelectric Plant São Simão-GO. Was used to analyze the image of the municipality that comes from the satellite Landsat 5 TM sensor, using the Geographic Information System (GIS) Brazilian SPRING, version 5.2.6, in the treatment of the image, making then the supervised classification for, then calculate the percentage of the types of land use and occupation.

KEY WORDS: Remote Sensing, natural vegetation, analysis.
\end{abstract}

1Discente do curso de Geografia da Faculdade de Ciências Integradas do Pontal FACIP/UFU aneto.mariano@gmail.com

2Discente do curso de Geografia da Faculdade de Ciências Integradas do Pontal FACIP/UFUakinod@yahoo.com

3Docente do curso de Geografia da Faculdade de Ciências Integradas do Pontal FACIP/UFU (Orientadora) jussara@pontal.ufu.br 


\section{LÍMITES Y MEDICIÓN DE LA VEGETACIÓN NATURAL CERCA DE PARANAIBA RÍO EN EL MUNICIPIO DE SÃO SIMÃO-GO}

\section{RESUMEN}

Este trabajo fue desarrollado para la disciplina Teledetección en el tercer período, por supuesto, la Geografía, la Faculdade de Ciências Integradas do Pontal(FACIP), Campus fuera de la sede de la Universidade Federal de Uberlândia (UFU). El mapeo y análisis de áreas de preservación permanente son fundamentales para garantizar la calidad de los recursos hídricos. Por lo tanto, el objetivo de este estudio fue definir y cuantificar las áreas de vegetación natural en las cercanías de Rio Paranaíba, más precisamente en el lago de Central Hidrelétrica de São Simão-GO. Se utilizó para analizar la imagen del municipio que viene del sensor de satélite Landsat 5 TM, utilizando el Sistema de Información Geográfica (SIG) SPRING brasileña, versión 5.2.6, en el tratamiento de la imagen, por lo que entonces la clasificación supervisada para, entonces calcular el porcentaje de los tipos de uso de la tierra y la ocupación.

PALABRAS CLAVE: Teledetección, análisis, vegetación natural

\section{INTRODUÇÃO}

O município de São Simão está localizado na região sul do estado de Goiás, possui as seguintes coordenadas geográficas: Latitude $18^{\circ} 59^{\prime} 28^{\prime \prime} \mathrm{S}$ e Longitude $50^{\circ}$ 32' 37" W tem uma população de 18.804 habitantes, de acordo com o IBGE (2014) e é banhado pelo rio Paranaíba.

No município está presente a Usina Hidrelétrica de São Simão, que situa-se a $280 \mathrm{~km}$ de Uberlândia. O reservatório se estende até a barragem de Cachoeira Dourada-GO e abrange os municípios de Bom Jesus de Goiás, Cachoeira Dourada, Gouvelândia, Inaciolândia, Paranaiguara e Quirinópolis no estado de Goiás e Cachoeira Dourada, Capinópolis, Gurinhatã, Ipiaçu, Ituiutaba e Santa Vitória no estado de Minas Gerais. Situada no Rio Paranaíba, a UHE iniciou sua operação em 1978 e tem capacidade de geração de 1.710 MW, operando com 06 unidades geradoras e seu reservatório apresenta um volume útil de 5,54 bilhões de $\mathrm{m}^{3}$ (CEMIG, 2008).

O Novo Código Florestal Brasileiro (Lei N. 12.651 de 2012) define como Área de Preservação Permanente (APP), as faixas marginais de qualquer curso d'água natural perene e intermitente, excluídos os efêmeros, desde a borda da calha do leito regular com largura mínima de 30 metros para cursos d'água com até 10 metros de largura, 50 metros para cursos d'água que possuam entre 10 e 50 metros 
de largura e 100 metros para os que possuam entre 50 e 200 metros de margem a margem (BRASIL, 2012).

Também devem ser mantidas APP's nas áreas no entorno das nascentes e dos olhos d'água perenes, qualquer que seja sua situação topográfica, no raio mínimo de 50 metros. A Reserva Legal é definida como a porção de vegetação nativa a ser mantida obrigatoriamente em qualquer imóvel rural, no caso das áreas de Cerrado a Lei N. 12.651 exige o mínimo de 20\% com relação a área total da propriedade (BRASIL, 2012) .

A Lei N. 12.651 estipula em seu artigo $4^{\circ}$, inciso III, que no caso de reservatórios artificiais, decorrentes de barramento ou represamento de cursos d'água naturais, a APP a ser preservada é definida na licença ambiental do empreendimento.

Com o represamento dos rios, ocorre a destruição da vegetação da margem e a inundação das lagoas marginais, além da transformação do antigo ecossistema lótico para um novo ecossistema lêntico ou semi-lêntico, implicando em grandes alterações físicas, químicas, limnologias e ambientais (TUNDISI, 1988)

Figura 1. Usina Hidrelétrica de São Simão.

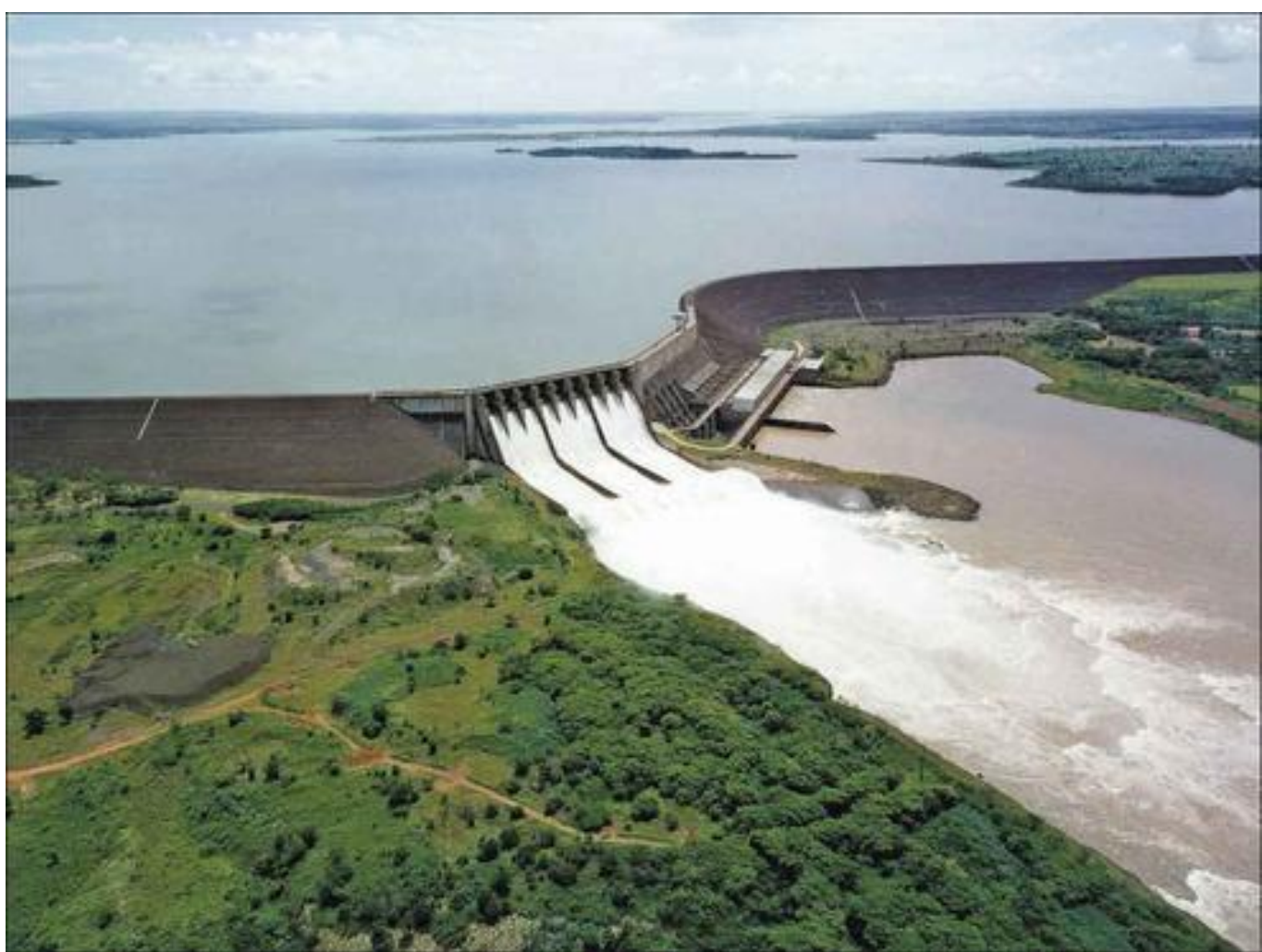

Fonte: CEMIG (2008) 


\section{DISCUSSÃO}

O presente trabalho tem como objetivo principal delimitar e quantificar as áreas de vegetação natural na região próxima ao rio Paranaíba, mais precisamente no lago da Usina Hidrelétrica de São Simão-GO. O tratamento da imagem e consequentemente o mapeamento do uso e ocupação do solo, foi possibilitado pela utilização do Sistema de Informações Geográficas (SIG) SPRING 5.2.6. A imagem do sensor TM/Landsat5,adquirida gratuitamente no site do Instituto Nacional de Pesquisas Espaciais (INPE, 2014), teve sua data de passagem em Junho de 2008. $O$ processamento digital da imagem incluiu os seguintes procedimentos metodológicos: a geração da composição colorida 3R2G1B; a aplicação de contraste linear; o recorte da área de interesse; a segmentação de imagens utilizando os valores de similaridade 10 e área 10 , e; a classificação supervisionada, por regiões, pelo método de Bhattacharya (SANTOS; PELÚZIO; SAITO, 2010).

De acordo com Rosa (2009) "A classificação de imagens refere-se à utilização de computadores para a interpretação de imagens de sensoriamento remoto, quando são atribuídos significados aos pixels, em função das características numéricas".

Figura 2. Delimitação da área de estudo.

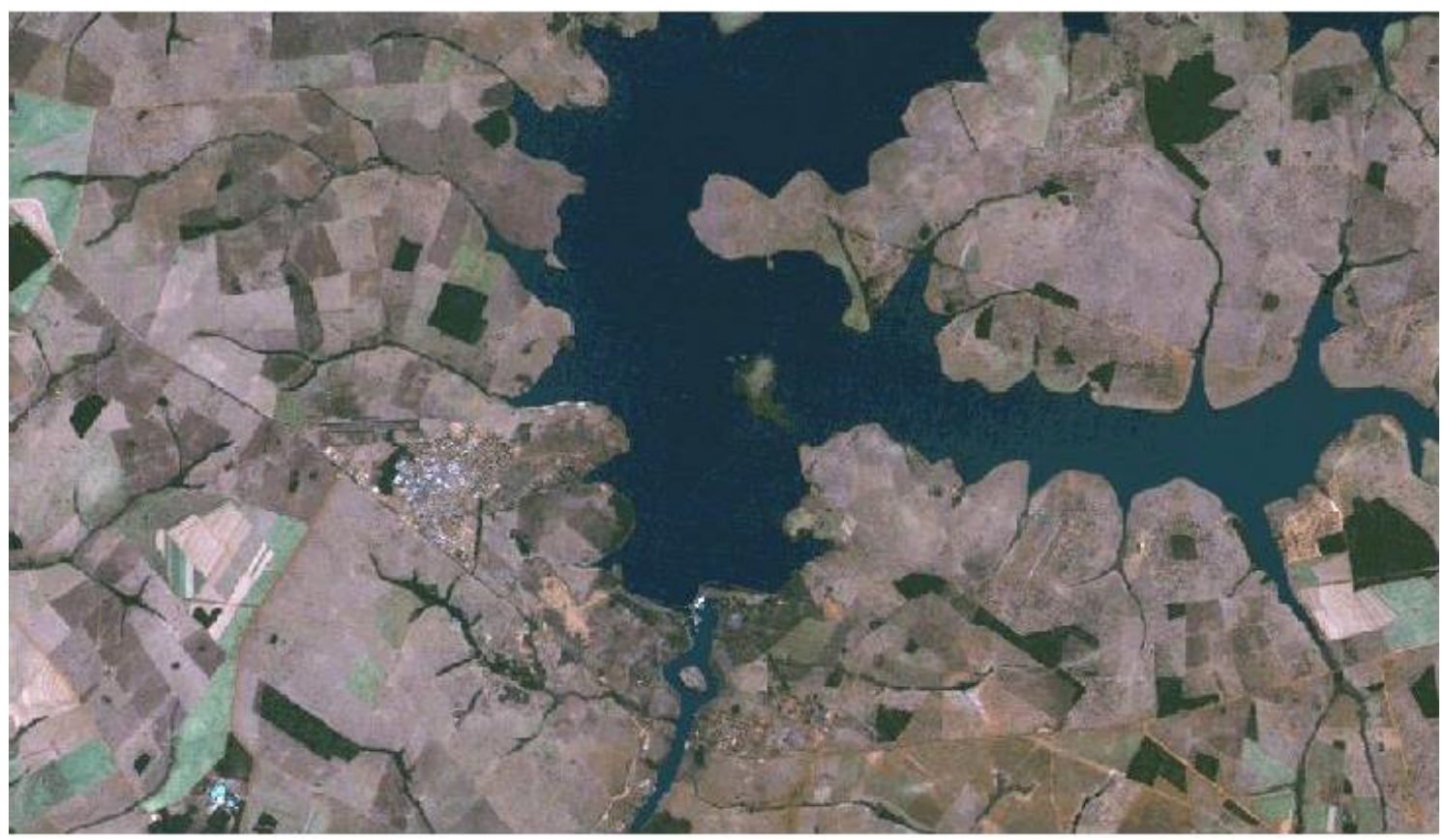

Fonte: Mapeamento do uso do solo e ocupação da terra no SIG SPRING 5.2.6

Org.: NETO, A. M. F. (2015) 
Após a segmentação da imagem (figura 3), que resultará em regiões de pixels semelhantes, na classificação supervisionada, os pontos de uma imagem são associados a uma classe ou grupo, chamado aqui de categorias de uso, as quais podem ser: água, culturas anuais, culturas perenes, vegetação nativa, pastagem e outros.

\begin{abstract}
A classificação supervisionada consiste na identificação das classes de informação (tipos de cobertura do solo) presentes na imagem e posteriormente é desenvolvida uma caracterização estatística das refletâncias para cada classe de informação. Nesse tipo de classificação o analista identifica os tipos específicos de cobertura do solo já conhecidos da área de estudo, ou seja, é necessário que se tenha conhecimento sobre as classes na imagem (ROSA, 2009)
\end{abstract}

Figura 3. Segmentação da imagem a partir dos valores de similaridade 10 e área 10.

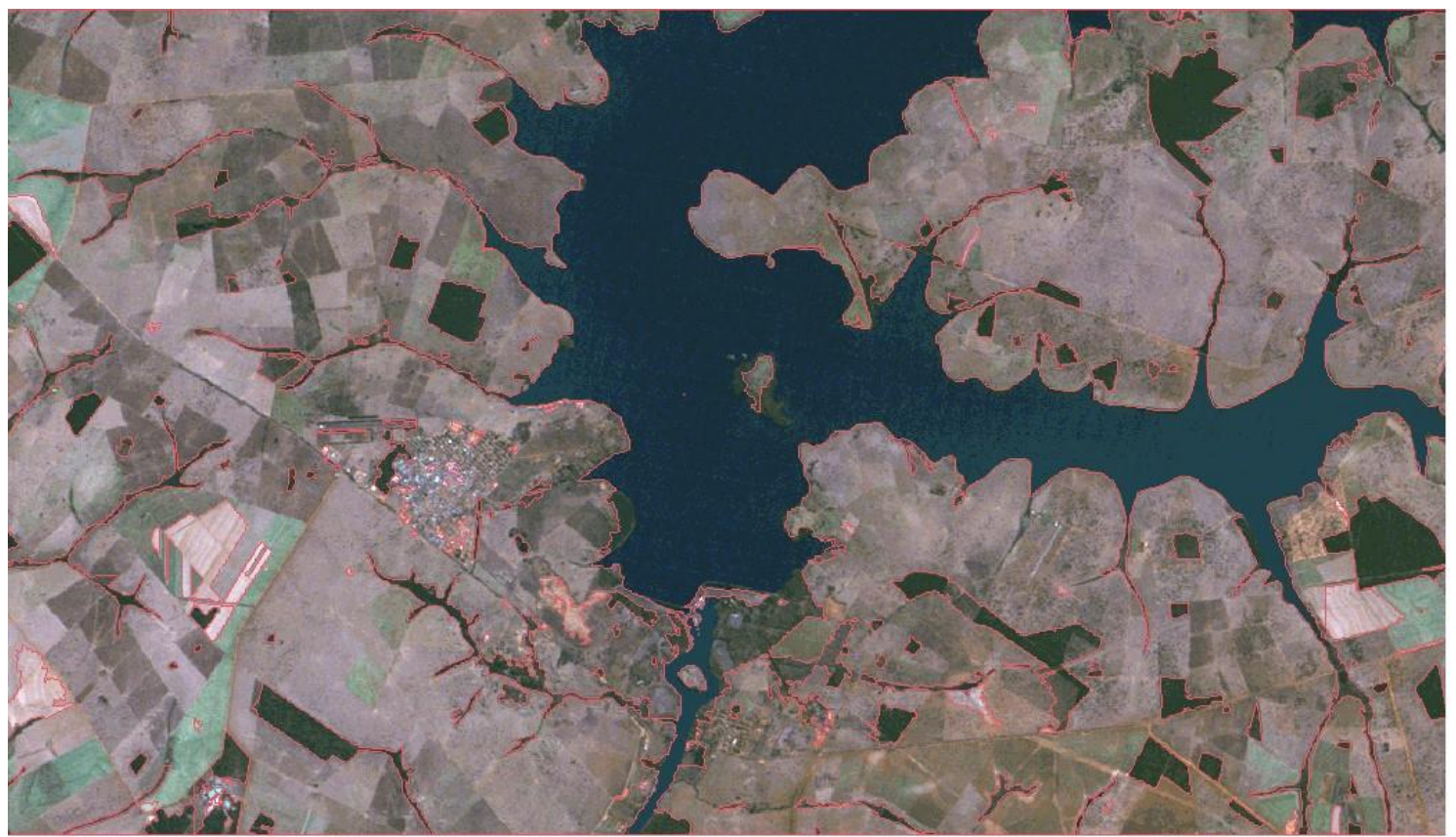

Fonte: Mapeamento do uso do solo e ocupação da terra no SIG SPRING 5.2.6

Org.: NETO, A. M. F. (2015)

As categorias de uso definidas para a fotointerpretação e posterior mapeamento foram: vegetação natural, água e outros usos.

\title{
3. RESULTADOS
}

Após o processamento digital da imagem das proximidades do Rio Paranaíba, confeccionou-se o mapa de uso e ocupação do solo. "O levantamento do 
uso e ocupação do solo de uma região tornou-se um aspecto de interesse fundamental para a compreensão dos padrões de organização do espaço" (ROSA, 2009).

Conforme verificado no Mapa 1, muitos trechos margeantes aos cursos d'água, denominados Áreas de Preservação Permanente (APP), estão totalmente desprovidos de vegetação nativa. Essa constatação remete a preocupação ambiental sobre a manutenção dos recursos hídricos associados à preservação da vegetação natural, que é exigida em lei. No caso de reservatórios artificiais, decorrentes de barramento ou represamento de cursos d'água naturais, a APP a ser preservada é definida na licença ambiental do empreendimento.

Essa situação é alarmante quando se verifica a inexistência de APPs às margens do lago da usina de São Simão-GO. Os impactos ambientais associados a isso podem incluir o assoreamento do lago, o desmoronamento das encostas, a perda de fauna e flora, dentre outros. 
Mapa 1: Mapa de ocupação do solo.

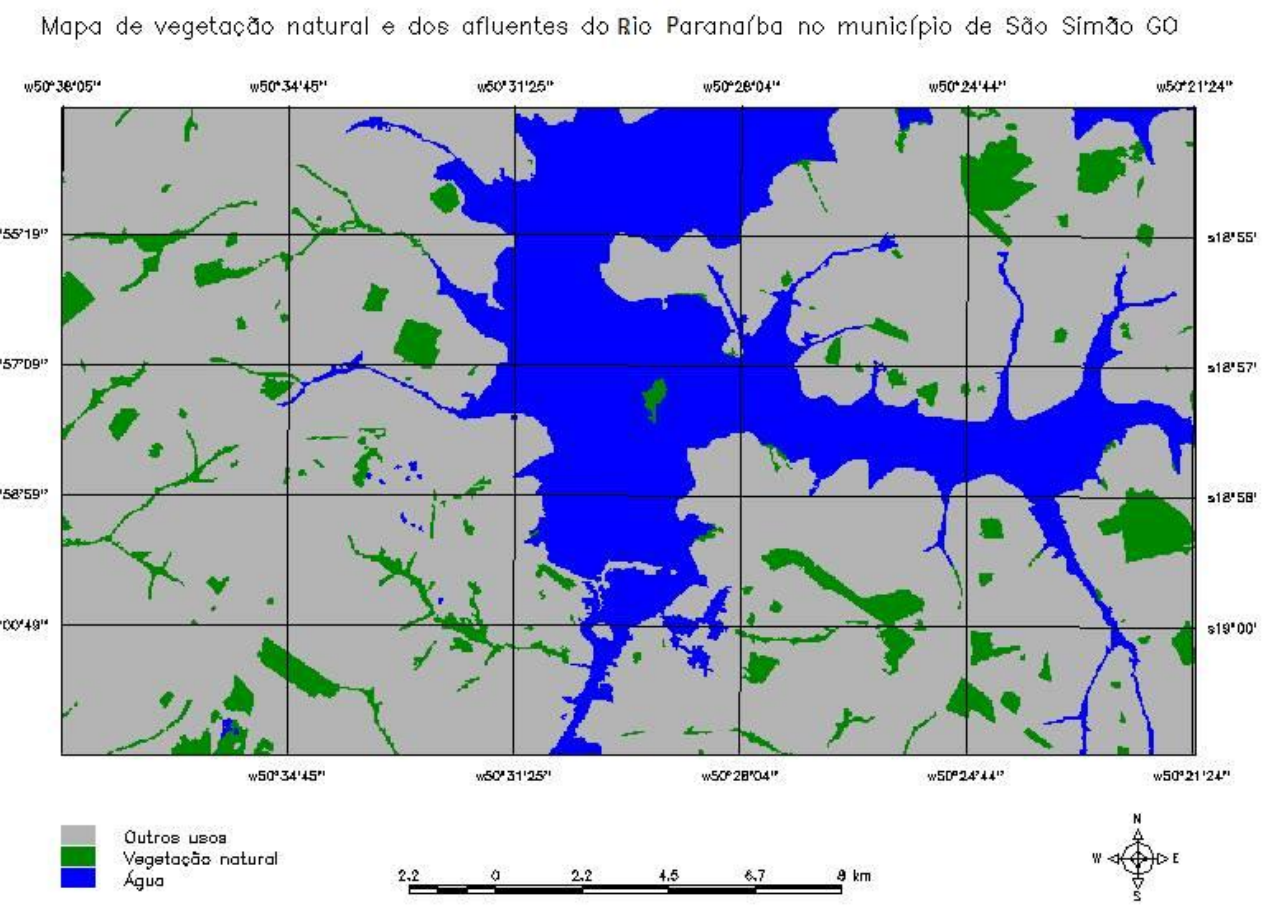

Fonte: Mapeamento do uso do solo e ocupação da terra no SIG SPRING 5.2.6

Org.: NETO, A. M. F. (2015)

Com a quantificação dos resultados obtidos conclui-se que as áreas dos diferentes usos do solo no perímetro delimitado para estudo possuem os seguintes percentuais:

Quadro 1 - Classes de uso e ocupação do solo e respectivas áreas.

\begin{tabular}{|c|c|c|}
\hline Classe & Área (ha) & Porcentagem (\%) \\
\hline Água & $19.956,89$ & $22,77 \%$ \\
\hline Vegetação natural & $13.295,17$ & $15,17 \%$ \\
\hline Outros Usos & $54.392,82$ & $62,06 \%$ \\
\hline Total & $87.645,55$ & $100 \%$ \\
\hline
\end{tabular}

Fonte: Mapeamento do uso do solo e ocupação da terra no SIG SPRING

5.2 .6

Org.: NETO, A. M. F. (2015)

O mapeamento realizado para a área de pesquisa revelou que somente $15,17 \%$ da área é coberta por vegetação nativa, estando aí representadas as Áreas de Preservação Permanente, Reserva Legal e demais formas de vegetação natural de Cerrado. 


\section{CONSIDERAÇÕES FINAIS}

Com avanço do "progresso" e com as cada vez mais presentes monoculturas, os espaços de vegetação natural vem sendo progressivamente degradados seja as grandes áreas florestais ou até mesmo as matas ciliares que deveriam ser preservadas e, consequentemente, os cursos d'água, que são essenciais para a manutenção da qualidade de vida dessa e das futuras gerações.

Sendo assim, no mapa elaborado, esse aspecto fica muito evidente uma vez que a área de vegetação natural é bem menor que as outras áreas citadas, até mesmo nas margens do rio onde deveriam ser totalmente preservadas.

Portanto fica claro o déficit de áreas verdes naturais nesse perímetro, visto que com o processo de represamento do rio houve uma enorme devastação de toda área de vegetação natural. Tal fator tem como consequência a migração de animais silvestres para a área urbana, a elevação da temperatura na micro região, degradação do solo, dentre outros impactos ambientais. 


\section{REFERÊNCIAS BIBLIOGRÁFICAS}

BELTRAME, A. da V. Diagnóstico do meio físico de bacias hidrográficas: modelo e aplicação. Florianópolis: UFSC, 1994.

BRASIL. Novo Código Florestal Brasileiro. Lei N. 12.651, de 25 de maio de 2012. Disponível em: <http://www.planalto.gov.br/ccivil_03/_ato2011-2014/2012/lei/L12651compilado.htm >. Acesso em: 20 de out de 2014.

CEMIG. Companhia Energética de Minas Gerais. Coleta de dados da Usina Hidrelétrica de São Simão-GO. Disponível em: < http://www.cemig.com.br/> Acesso em: 20 de nov. 2014.

COSTA, N. M. C. da; SILVA, J. X. Geoprocessamento aplicado à criação de planos de manejo: o caso do Parque Estadual da Pedra Branca( RJ). In: ZAIDAN, R. T.; XAVIER DA SILVA, J. Geoprocessamento e análise ambiental: aplicações. Rio de Janeiro: Bertrand Brasil, p. 66-114, 2004.

GONÇALVES,C. R. Monitoramento da ictofauna: Usina Hidrelétrica de São Simão. CEMIG. 2008. Disponível em: <http://www.cemig.com.br/>. Acesso em: 08 out. 2014.

IBGE. Instituto Brasileiro de Geografia e Estatística. Coleta de dados sobre o município de São Simão-GO. Disponível em: <http://www.ibge.com.br>. Acesso em: 12 de nov de 2014.

INPE. Instituto Nacional de Pesquisas Espaciais. Aquisição das imagens do satélite TM/Landsat 5. Disponível em: <http://www.inpe.br/>. Acesso em: 20 de mai de 2014.

PRUDENTE, T. D.; ROSA. R. Geoprocessamento e sensoriamento remoto aplicados no mapeamento de uso da terra e cobertura vegetal do município de Tupaciguara-MG. In: Anais. XII Simpósio Brasileiro de Geografia Física Aplicada. Natal, Rio Grande do Norte, 2007.

ROSA, R. Introdução ao sensoriamento remoto. 7. ed. Uberlândia: EDUFU, 2009.

SANTOS, A. R.; PELUZIO, T. M. O.; SAITO, N. S. SPRING 5.1.2: Passo a passo. Alegre, ES, CAUFES, 2010. 153p. Disponível em: <http://www.mundogeomatica.com.br/Livros/Livro_Spring_

5.1.2_Aplicacoes_Praticas/LivroSPRING512PassoaPassoAplicacaoPratica.pdf>. Acesso em: 23 de mar de 2014.

SILVA, J. X.; ZAIDAN, R. T. Geoprocessamento \& análise ambiental: aplicações. Rio de Janeiro: Bertrand, 2004.

SBSR. Simpósio Brasileiro de Sensoriamento Remoto. Disponível em: <http://www.dsr.inpe.br/sbsr2007/>. Acesso em: 15 de mar de 2014.

TUNDISI, J. G. Limnologia e manejo de represas. São Paulo, Academia de Ciências de São Paulo, 1988. 